\title{
Drone Injuries and Safety Recommendations ${ }^{1}$
}

\section{Serap Gorucu and Yiannis Ampatzidis ${ }^{2}$}

Recreational and commercial drones have become very popular in the last decade. This publication presents drone-related injury statistics and safety recommendations to prevent drone-related injuries. This publication targets the public and drone users.

\section{Introduction}

Unmanned Aircraft Systems, or drones, have become very popular in the last decade. They are used for recreational, scientific, commercial, and military operations. According to the US Department of Transportation, Federal Aviation Administration, the total number of drones registered in the United States was more than 1.7 million in 2020 (USDOT 2020a).

Drones can cause injuries because of their quick movements, rotating parts, sharp blades, and edges. Injuries may happen not just to the user, but to anyone else in the area. They can also cause some hearing problems (Technische Beratung Ingenieurburo 2020). There have been numerous injuries from drone-related incidents reported by the media: "A toddler on swings injured by drone that fell from sky," "Utah man injured after drone flies into his face downtown," and "A woman was knocked unconscious when she was struck by the small drone as she watched the annual parade in 2015" (NYpost 2018; USnews 2019; TheSeattleTimes 2017).
The purpose of this report isto examine drone-related injuries treated in the US emergency departments and provide safe drone operations recommendations.

\section{Method}

This cross-sectional study used data for patients treated from January 1, 2015 to December 31, 2019 collected from the US Consumer Product Safety Commission and the National Electronic Injury Surveillance System (NEISS). As an analysis of publicly available de-identified data, this study is exempt from our Institutional Review Board.

The NEISS collects emergency department data from approximately 100 hospitals selected as a probability sample of all 5,000+ US hospitals with emergency departments (ED) (NEISS 2020). In addition to patient demographics, incident date, diagnosis, injury location, and patient disposition, the NEISS also contains a brief narrative describing incident scenarios (NEISS Coding Manual 2019). Lacking a specific code for drones, the NEISS database includes drones in the "toy vehicles (excluding riding toys)" code 5021 (NEISS Coding Manual 2020). We queried the NEISS for years 2015-2019, and the search term "drone" was used to identify drone-related injuries from the patient narrative. There were 89 unweighted cases identified using this criterion. All patients under the age of 18 were defined as pediatric patients; other patients were classified as adult patients.

1. This document is AE560, one of a series of the Department of Agricultural and Biological Engineering, UF/IFAS Extension. Original publication date June 2021. Visit the EDIS website at https://edis.ifas.ufl.edu for the currently supported version of this publication.

2. Serap Gorucu, assistant professor, risk analysis, safety, and health of agricultural systems, Department of Agricultural and Biological Engineering; and Yiannis Ampatzidis, associate professor, Department of Agricultural and Biological Engineering, UF/IFAS Southwest Florida Research and Education Center; UF/IFAS Extension, Gainesville, FL 32611.

The Institute of Food and Agricultural Sciences (IFAS) is an Equal Opportunity Institution authorized to provide research, educational information and other services

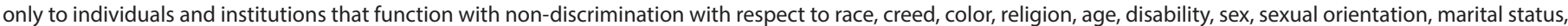

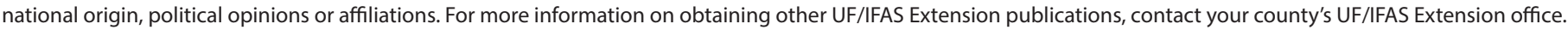
U.S. Department of Agriculture, UF/IFAS Extension Service, University of Florida, IFAS, Florida A \& M University Cooperative Extension Program, and Boards of County Commissioners Cooperating. Nick T. Place, dean for UF/IFAS Extension. 
National estimates were created using weights provided by the NEISS. The complex samples function of SPSS was used to obtain the estimated number of injuries with $95 \%$ confidence intervals (95\% CI).

\section{Results}

From 2015 to 2020, there were approximately 4,250 drone injuries (95\% CI, 3,625 to 3,790) (Figure 1). Of the injured patients, $21 \%$ were younger than 18 years old and $84 \%$ of the patients were male.

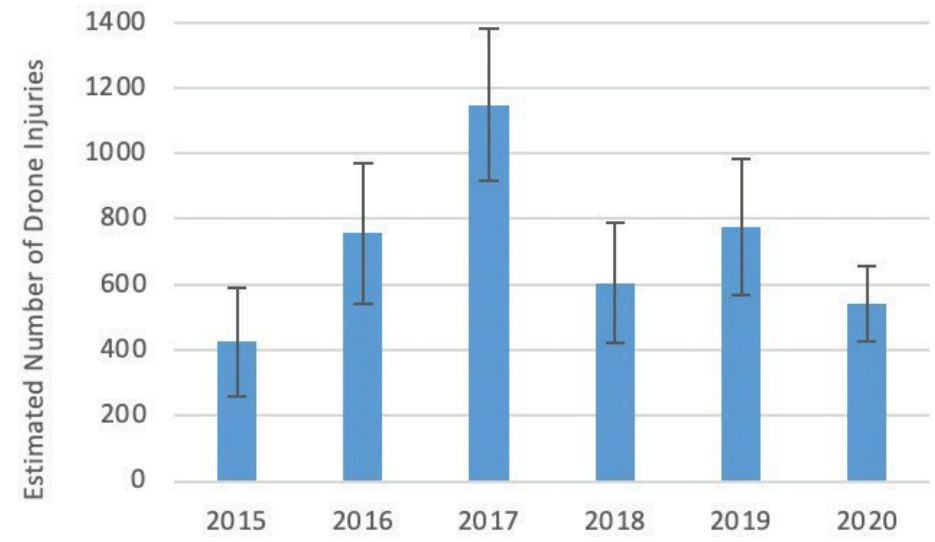

Figure 1. Yearly distribution of drone-related injuries treated in the US emergency departments.

Credits: Serap Gorucu, UF/IFAS

The most common injury diagnoses were lacerations (72\%) followed by contusion/abrasion (10\%), strain/sprain (5\%), and internal injury (5\%). The most injured body parts were upper extremities (mostly fingers [56\%]), head (24\%), lower extremities (14\%), and trunk (6\%).

Most patients (95\%) with a drone-related injury were treated and released. Only one patient was killed by electrocution while trying to retrieve the drone from power lines with a metal pole.

Some injury case examples from the NEISS database are given below.

- "21-month-old female patient was hit in the right eye by drone."

- "29-year-old male had electrical burns while retrieving a drone that was entangled in wires and got shocked."

- "40-year-old male patient hit in the head by a flying drone in the street."

- "31-year-old male patient playing with a drone and caught finger in blades, had lacerations to finger."

\section{Safety Recommendations}

Recommendations by the US Department of Transportation, Federal Aviation Administration (USDOT FAA) are given below (FAA 14 CFR Part 107) (USDOT 2020b).

- Do not operate the drone in a careless or reckless manner.

- Keep your drone within sight and operate one drone at a time.

- Do not fly a drone over people.

- Fly during daylight or in twilight if your drone has anti-collision lighting.

- Do not operate the drone from a moving vehicle.

- Do not fly the drone more than $400 \mathrm{ft}$ above the ground.

Additional safety recommendations:

- Keep your distance when taking off or landing and keep at least $16 \mathrm{ft}$ of safety distance to all people around the drone (Technische Beratung Ingenieurburo 2020).

- When using drones around young children, be especially cautious.

- Keep your fingers and other body parts away from a moving propeller. Propeller guards can create a safe zone and provide some protection from propeller injuries.

- Stay away from the power lines. If a drone becomes entangled in a power line, do not try to retrieve it.

- Before you operate the drone, read the user manual for safe operation instructions.

Additional information on safe and responsible drone use is available from Know Before You Fly (https://knowbeforeyoufly.org/home), an educational campaign providing prospective users with information and guidance.

For more instructions on how to use a drone for agricultural applications, refer to the publications below.

- Kakarla, De Morais Nunes, and Ampatzidis (2019) (https://edis.ifas.ufl.edu/ae535)

- Fletcher and Singh (2020) (https://edis.ifas.ufl.edu/ publication/ae541)

- Singh and Fletcher (2021) (https://edis.ifas.ufl.edu/ publication/ae552)

- Singh and Fletcher (2021) (https://edis.ifas.ufl.edu/ publication/ae553)

\section{Summary}


Over the study period, more than 3,700 patients were treated in US emergency departments for drone-related injuries. The injured patients were mostly adult males, and the most common injury was lacerations to the fingers.

Refer to the FAA's Small Unmanned Aircraft Systems Rule (Part 107) to understand the regulations, operating requirements, and procedures for flying drones safely (https:// www.ecfr.gov/cgi-bin/text-idx?SID=dc908fb739912b0e6dcb $7 \mathrm{~d} 7 \mathrm{~d} 88 \mathrm{cfe} 6 \mathrm{a} 7 \& \mathrm{mc}=$ true\&node=pt14.2.107\&rgn=div5).

\section{References}

Fletcher, J., and A. Singh. 2021. "Applications of Unmanned Aerial Systems in Agricultural Operation Management: Part I: Overview." EDIS 2021(1). https://edis.ifas.ufl.edu/ publication/ae541

Kakarla, S. C., and Y. Ampatzidis. 2018. Instructions on the Use of Unmanned Aerial Vehicles (UAVs). AE527. Gainesville: University of Florida Institute of Food and Agricultural Sciences. https://edis.ifas.ufl.edu/ae527

Kakarla, S. C., L. De Morais Nunes, and Y. Ampatzidis. 2019. Preflight and Flight Instructions on the Use of Unmanned Aerial Vehicles (UAVs) for Agricultural Applications. AE535. Gainesville: University of Florida Institute of Food and Agricultural Sciences. https://edis.ifas.ufl.edu/ae535

NYpost. 2018. "Toddler on Swings Injured by Drone That Fell from Sky: Cops.” Accessed on October 29, 2020. https:// nypost.com/2018/08/06/toddler-on-swings-injured-bydrone-that-fell-from-sky-cops/

The Seattle Times. 2017. "Man Convicted in Drone Crash That Injured Woman during Seattle's Pride Parade." Accessed on October 29, 2020. https://www.seattletimes.com/ seattle-news/crime/man-convicted-in-drone-crash-thatinjured-woman-during-seattles-pride-parade/

Singh, A., and J. Fletcher. 2021. "Applications of Unmanned Aerial Systems in Agricultural Operation Management: Part III: Best Practices for Efficient Aerial Surveying." EDIS 2021(1). https://edis.ifas.ufl.edu/publication/ae553

Technische Beratung Ingenieurburo. 2020. "Drone Dangers, Risk and Injuries.” Accessed on October 29, 2020. https:// www.technik-consulting.eu/en/analysis/drone_risks.html

US CPSC. 2019. "NEISS Coding Manual." Accessed on September 1, 2020. https://www.cpsc.gov/s3fs-public/2019_ NEISS_Coding_Manual.pdf?kF045AF8hSkt_vPuRHjyIbiet. BzcT_v
US CPSC. 2020. "NEISS Highlights, Data and Query Builder." Accessed on May 28, 2021. https://www.cpsc.gov/ cgibin/NEISSQuery/home.aspx

USDOT. 2020a. "UAS by the Numbers." Accessed on October 29, 2020. https://www.faa.gov/uas/resources/ by_the_numbers/

USDOT. 2020b. "Fact Sheet - Small Unmanned Aircraft Systems (UAS) Regulations (Part 107).” Accessed on October 29, 2020. https://www.faa.gov/news/fact_sheets/ news_story.cfm?newsId=22615

USnews. 2019. "Utah Man Injured After Drone Flies into His Face Downtown." Accessed on October 29, 2020. https://www. usnews.com/news/best-states/utah/articles/2019-12-04/ utah-man-injured-after-drone-flies-into-his-face-downtown 